\title{
Total lesion of the radial nerve in the arm with preservation of the superficial radial nerve sensory action potential
}

\author{
Lesão total do nervo radial no braço com preservação do potencial sensitivo do \\ nervo radial superficial
}

Eduardo Rodrigues Davidovich, Marcelo Ribeiro Caetano, Osvaldo J. M. Nascimento

\begin{abstract}
Neurology and Neuroscience Clinical Research Sub-Unit (Neuro-UPC), Hospital Universitário Antonio Pedro, Universidade Federal Fluminense (UFF), Rio de Janeiro RJ, Brazil.

Correspondence:Osvaldo José Moreira do Nascimento; Rua Siqueira Campos 53 / 1.204;22031-070 Rio de Janeiro RJ - Brasil; E-mail:osvaldo_nascimento@hotmail.com Conflict of interest: There is no conflict of interest to declare.
\end{abstract}

Received 27 March 2012; Received in final form 19 June 2012; Accepted 26 June 2012

The electrodiagnostic test (EDX) interpretation of focal peripheral nerve lesions is based on detailed knowledge of nerve and muscle anatomies.

The occurrence of anatomical variations can result in the misinterpretation of EDX analysis leading to diagnostic error. The aim of this report was to call attention for an anatomical variation in which the lateral antebrachial cutaneous nerve (LACN) innervates the radial border of the dorsum of the hand, in addition to or replacing the superficial radial nerve (SRN). From an anatomic point of view, this anatomic variation is well-described. On the other hand, there is no neurophysiological technique able to confirm or deny its occurrence.

\section{CASE REPORT}

A 54-year-old woman was referred to the Neurology Department - Antonio Pedro University Hospital for an EDX evaluation of a possible left radial nerve lesion. She underwent elective surgery to remove a lipoma in her left arm, 30 days before the consultation. She had no complaints regarding the peripheral nervous system prior to surgery. At the immediate postoperative period, she was unable to extend her wrist and left hand fingers, which is compatible with radial nerve injury. Numbness was not present in the dorsum of left hand. This clinical picture remained unchanged until the neurophysiological consultation. Physical examination revealed extension paralysis of the left wrist and fingers. Left arm extension strength was normal.

EDX showed a normal sensorial nerve conduction in the SRN (first finger and in the dorsum of the hand), median, and ulnar nerves of both hands. The motor nerve conduction was not present in the left radial nerve and was normal in the right, median, and ulnar nerves (Table). The needle
Table. Study findings of the sensorial nerve conduction.

\begin{tabular}{lcc}
$\begin{array}{c}\text { Sensory nerve conduction } \\
\text { SRN first finger }\end{array}$ & $\begin{array}{c}\text { Right } \\
3.0 \mathrm{~ms} / 12 \mu \mathrm{V}\end{array}$ & $\begin{array}{c}\text { Left } \\
2.8 \mathrm{~ms} / 15 \mu \mathrm{V}\end{array}$ \\
\hline SRN hand dorsum & $2.7 \mathrm{~ms} / 15 \mu \mathrm{V}$ & $2.8 \mathrm{~ms} / 19 \mu \mathrm{V}$ \\
Median nerve third finger & $3.3 \mathrm{~ms} / 20 \mu \mathrm{V}$ & $3.4 \mathrm{~ms} / 22 \mu \mathrm{V}$ \\
Ulnar nerve fifth finger & $3.1 \mathrm{~ms} / 25 \mu \mathrm{V}$ & $3.2 \mathrm{~ms} / 21 \mu \mathrm{V}$ \\
\hline
\end{tabular}

SRN: superficial radial nerve.

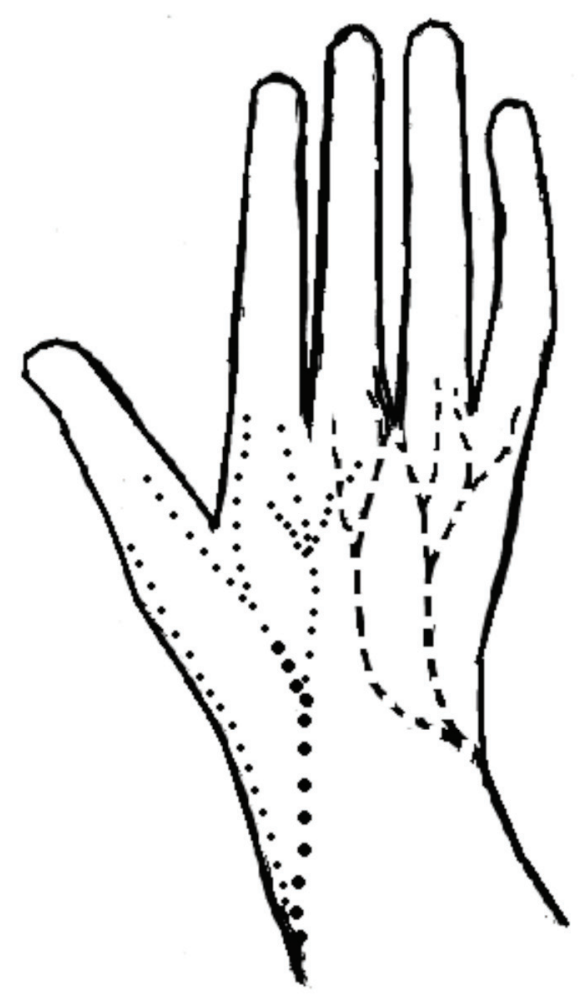

Figure. In left (dot lines), the lateral antebrachial cutaneous nerve branches. In the right, the dorsal branches of the ulnar nerve are represented. There are no superficial radial nerve branches on the dorsum of the hand. Modified from the original Appelton case. 
electromyography showed positive sharp waves, fibrillations, and absence of functioning motor units in muscles innervated by the left radial nerve, with the exception of the triceps.

\section{DISCUSSION}

Appleton $^{1}$, in 1911, reported the first description of this anatomical variation based on a forearm dissection. He found only the posterior radial nerve interosseous branch with absent SRN, below the elbow. On the dorsum of the hand, the LACN extended out beyond its usual distribution to supply the SRN territory (Figure). The dorsal branch of the ulnar nerve had greater ramifications than those usually observed by completing the innervation of the dorsal hand. Other authors ${ }^{2-5}$ have studied the distribution of LACN and SRN in the dorsum of the hand and confirmed the existence of this anatomical variation.

In our assessment, the occurrence of an anatomical variation involving LACN and SRN, in which the cutaneous territory of the SRN is wholly or partially supplied by the LACN, can explain the data obtained in the presence of total lesion of the radial nerve in the arm. In cases of proximal radial nerve injury, the occurrence of this variation may lead to diagnostic errors in the EDX study, in which a total axonal damage may erroneously be considered as partial lesion with a conduction block component.

\section{References}

1. Appleton AB. A case of abnormal distribution of the $n$. musculocutaneous, with complete absence of the ramus cutaneous n. radialis. J Anat Physiol 1911;46:89-94.

2. Stopford JSB. The variation in distribution of the cutaneous nerves of the hand and digits. J Anat 1918;53:14-25.

3. Mackinnon SE, Dellon AL. The overlap pattern of the lateral antebrachial cutaneous nerve and the superficial branch of the radial nerve. J Hand Surg 1985;10:522-526.
4.

Huanmanop T, Agthong S, Luengchawapong K, et al. Anatomic characteristics and surgical implications of the superficial radial nerve. J Med Assoc Thai 2007;90:1423-1429.

5. Yogesh A, Marathe R, Pandit S. Musculocutaneous nerve substituting for the distal part of radial nerve: a case report and its embryological basis.J Neurosci Rural Pract 2011;2:74-76.

\section{Marfanoid features and X-linked mental retardation associated with craniofacial abnormalities: the Lujan-Fryns syndrome}

\section{Aspectos marfanoides e retardo mental ligado ao $\mathrm{X}$ associados a anormalidades craniofaciais: síndrome de Lujan-Fryns}

Paula Macedo Dieckmann, Lara Carneiro de Lucena, Livia Almeida Dutra, José Luiz Pedroso, Orlando G.P. Barsottini

Department of Neurology, Universidade Federal de São Paulo (Unifesp), São Paulo SP, Brazil.

Correspondence: José Luiz Pedroso; Rua Botucatu 740;04023-900 São Paulo SP - Brasil; E-mail: zeluizpedroso@yahoo.com.br

Conflict of interest: There is no conflict of interest to declare.

Received 01 April 2012; Received in final form 28 June 2012; Accepted 07 July 2012

Marfanoid features associated with mental retardation are often a diagnostic challenge for general neurologists, since several genetic and inborn metabolic diseases present this clinical spectrum. Some of these diseases have typical clinical markers that may aid diagnosis. For instance, Lujan-Fryns syndrome is a recessive $\mathrm{X}$-linked condition characterized by mental retardation, marfanoid habitus, and facial dysmorphisms ${ }^{1,2}$.

Herein, we described a male patient with marfanoid habitus and mental retardation, in whom the presence of facial dysmorphisms was the clue for diagnosing the Lujan-Fryns syndrome.

\section{CASE REPORT}

A 25-year-old man presented to the Division of General Neurology, at Universidade Federal de São Paulo, with developmental delay and learning disabilities since childhood. His family history was unremarkable and there was no parental consanguinity. He had another brother with possible marfanoid features and learning disabilities, and other three ones and a sister that had not been evaluated. A possible X-linked inherited disorder was suspected. On examination, the patient 